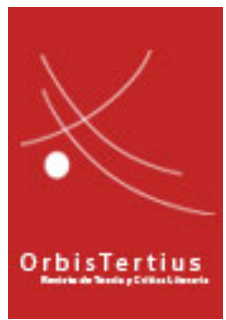

Orbis Tertius, vol. XXII, $n^{\circ}$ 25, e038, junio 2017. ISSN 1851-7811

Universidad Nacional de La Plata

Facultad de Humanidades y Ciencias de la Educación

Centro de Estudios de Teoría y Crítica Literaria

\title{
Sarissa Carneiro, Retórica del infortunio. Persuasión, deleite y ejemplaridad en el siglo XVI
}

\author{
Madrid-Frankfurt, Iberoamericana-Vervuert, 2015, Parecos y australes. \\ Ensayos de Cultura de la Colonia, 235 páginas.
}

\section{María Inés Aldao}

Siempre es de celebrar la aparición de un libro que se ocupe de crónicas de la conquista de América, más si propone abordar de lleno la cuestión retórica, mucho más si se aboca a textos poco trabajados en profundidad como los relatos de infortunios y naufragios de viajeros españoles y portugueses. Esta es la propuesta de Retórica del infortunio. Persuasión, deleite y ejemplaridad en el siglo XVI: volver a leer algunos textos postconquista a la luz de los preceptos retórico-poéticos conocidos por muchos aunque aplicados a la lectura textual por pocos.

El proyecto es ambicioso, pero el libro cumple con creces su objetivo. Su autora, la Doctora en Literatura por la Pontificia Universidad Cat ólica de Chile, Sarissa Carneiro, ha mostrado a lo largo de sus años de especialización en letras coloniales una férrea preocupación por las historias de la conquista de América, con especial atención en Chile, Brasil y la Península Ibérica. Retórica del infortunio, publicado por Iberoamericana Vervuert en 2015, es su último libro de una larga lista de trabajos sobre el período. En él, Carneiro estudia el concepto de "infortunio" en relatos de viaje, específicamente en el Libro de infortunios y naufragios de Historia general y natural de las Indias y tierra firme del mar océano de Gonzalo Fernández de Oviedo, finalizado hacia 1549, e História trágico-marítima en que se escrevem chronologicamente os Naufragios que tiverao as Naos de Portugal, depois que se poz em exercicio a Navegaçao da India, relatos recopilados por Bernardo Gomes de Brito hacia 1735-1736. Ambos textos relatan padecimientos marítimos sufridos durante el siglo XVI. 
El abordaje propuesto recorre la preceptiva retórica sobre la fortuna próspera y su otra variante, la fortuna adversa o infortunio, desde sus concepciones más antiguas hasta su recuperación entre los pensadores del siglo XVI. Carneiro rescata a los estudiosos más relevantes de este tema, nombres que remiten necesariamente a autores de la antigüedad, como Aristóteles, Cicerón y Quintiliano, leídos, interpretados, imitados y transformados a lo largo del siglo XVI. Juan Luis Vives, Miguel de Salinas, García Matamoros, Luis de Guzmán, Luis de Granada, López Pinciano, Agrícola, Erasmo de Rotterdam, Escalígero, por nombrar algunos de una larga lista, ingresan en el libro en un detallado análisis que ilumina la lectura de las crónicas en cuestión. La autora revisa, repone la información más importante de cada texto, hace hincapié en lo original de cada propuesta o en la contrapropuesta brindada, y ejemplifica atinadamente con los textos de Fernández de Oviedo y Gomes de Brito. Como afirma, las investigaciones más relevantes sobre Fortuna (Cassirer, Panofsky, Doren, entre otros) no han prestado suficiente atención a la codificación retórica de las crónicas de conquista o han caído en lugares comunes en su análisis. Entonces, la novedad de su trabajo reside en una revisión del aspecto retórico-discursivo del corpus para ahondar en una perspectiva crítica del "infortunio" que sólo se ha tratado con profundidad desde lo iconográfico.

El libro muestra la preeminencia que tuvo la "retórica del infortunio" en las crónicas de la época, en concreto, en desastres marítimos vinculados a la expansión ibérica y a los procesos de conquista y colonización americanos. Para la autora, el corpus amerita un estudio exhaustivo ya que las narraciones de naufragios escritas en el siglo XVI por portugueses y españoles evidencian un alto potencial simbólico en su contexto histórico-cultural hasta el momento no del todo visibilizado. Aborda, entonces, la preceptiva del infortunio desde las distintas partes de la retórica (especialmente, inventio, dispositio y elocutio) y desde las funciones del orador (docere, delectare, movere) proponiendo un énfasis en la pasión “dolorosa o placentera” que funge del infortunio y en los desplazamientos retóricos de los momentos de desventura, placer y deleite. Así, categorías como lo admirable, lo inesperable, el deleite "áspero" o el "placer trágico" e, incluso, los objetivos moralizantes de textos de fortuna adversa son tenidos en cuenta y leídos desde lo teórico y lo crítico.

La Primera parte del libro, llamada "Persuadir con el infortunio", está dedicada al "primer cronista oficial de Hispanoamérica”, Gonzalo Fernández de Oviedo. De su monumental Historia general y natural de las Indias, Carneiro se ocupa del último apartado, Infortunios y naufragios acaecidos en las mares de las Indias, islas y Tierra Firme del Océano, más conocido como Libro de infortunios y naufragios, en que se narran temeridades marítimas, muertes, milagros y relatos de sobrevivientes. Destaca Carneiro que en la edición definitiva de la Historia, los once capítulos que el Libro había tenido en la primera edición de 1535 se convirtieron en treinta. La crónica de Fernández de Oviedo ha sufrido en esos casi quince años, revisiones y adiciones y ha tenido la "fortuna”, por utilizar un tópico ad hoc, de que se extravíen los capítulos XI al XIX y los primeros párrafos del XX, amputación lamentable que han padecido muchas otras crónicas de Indias.

Luego de trazar una interesante relación entre el Libro de infortunios y naufragios y la iconografía de Fortuna próspera y adversa (que incluye el relevamiento de imágenes que acompañan el libro entero y que son de suma utilidad para el trabajo contrastivo que se sugiere), Carneiro propone que el texto funciona como peroración (e, incluso, como conquestio) del extenso discurso historiográfico de Oviedo, situado al final para exacerbar la moción del temor y la conmiseración como medios para la persuasión. En esta primera parte, Carneiro se pregunta qué pasiones entran en juego al narrar un caso de fortuna adversa y qué función cumple ese relato en un discurso que pretende ser persuasivo. En este punto, uno de los de mayor espesor teórico del libro, la autora realiza un interesante y muy completo estado de la cuestión sobre la importancia de la retórica y de la persuasión. Recorre postulados de autores como Aristóteles, Laurent Pernot, Benito Arias Montano y releva el concepto de "las pasiones” según varios textos fundamentales: Cicerón, la anónima Rhetorica ad Herennium, la Institutio oratoria de Quintiliano, la Artis rhetoricae 
compendiosa de Antonio de Nebrija o Del arte de hablar de Juan Luis Vives. Este último libro es analizado en profundidad para resaltar la conclusión de Vives de que entre las armas de la persuasión se encuentra la moción de los afectos, tanto para sosegarlos como para excitarlos, planteo que Carneiro utiliza en su abordaje. Así, mediante este análisis detallado, demuestra que desde la antigüedad ha sido objeto de discusión la pertinencia de un seguimiento retórico de las pasiones, que las emociones han tenido desde siempre un papel destacado en las retóricas (no solamente en las de tinte eclesiástico) y, finalmente, que el tratamiento de las pasiones daba lugar al del infortunio.

En su abordaje textual, la autora se muestra como gran conocedora de la crónica y de sus estrategias discursivas, observando que gran parte de los capítulos añadidos a posteriori de la primera edición tienen la clara intención de advertir a los lectores sobre los riesgos de buscar riquezas en América. En efecto, el objetivo del Libro es ese: mover al miedo recordando a los hombres su condición de mortales. Por eso, Carneiro no concuerda con parte de la crítica en que Fernández de Oviedo, en ese "monumental edificio historiográfico" que empieza con el feliz viaje de Colón y culmina plagado de infortunios, traza una línea que va del éxito al fracaso. Para la autora, es una línea que va de la vida a la muerte, muerte que pretende hacer que el lector se sumerja en la meditación, la trascendencia y la esperanza en la salvación. El mismo libro representaría, de esta manera, tanto la trayectoria de la conquista del Nuevo Mundo (oscilante entre ambos tipos de fortuna) como la de la vida misma.

En la Segunda Parte, "Deleite y ejemplaridad del infortunio”, la autora demuestra la importancia del género de relaciones de naufragios en las letras portuguesas entre los siglos XVI-XVIII, de larga duración y extensa popularidad. Muchas relaciones, señala, se imprimieron como pliegos sueltos y alcanzaron una notable difusión. Para Carneiro, no solo la tradición literaria sino, también, la retórica han aportado antecedentes fundamentales para la lectura profunda de estos textos. Si bien las codificaciones retóricas que analiza, aclara, no necesariamente explican el éxito editorial de dichas crónicas, sí contribuyen a la reconstrucción de los códigos que modelaron su primera legibilidad. Según la autora, los tratados retórico-poéticos del siglo XVI explicitaron, siguiendo la larga tradición proveniente de la antigüedad, los componentes que hacían de los textos sobre infortunios fuentes tanto de ejemplaridad como de deleite. Por eso, es posible asociar la delectación pretendida por estos textos no sólo al entretenimiento sino, también, al afán persuasivo.

En este punto, Carneiro se vale de distintas relaciones portuguesas de naufragios compiladas por Gomes de Brito en su História trágico-marítima que, según afirma, participan de estas codificaciones retórico-poéticas y perfilan una primera legibilidad de esos textos en términos de deleite y ejemplaridad. La escritora analiza los relatos de naufragios prestando especial atención a lo que tienen en común: la figura del espectador (partícipe o no del infortunio), la reiteración de ciertos verbos de visión y la constante recurrencia a la evidentia, fuente de "deleite áspero” y de persuasión. Señala, además, que la característica principal del género que mueve las pasiones de la compasión y el temor es, justamente, el cambio de la fortuna próspera hacia la adversa, la caída inevitable en la precariedad máxima de la condición humana. En los textos, este cambio repentino de fortuna es posible pero no esperado: si bien la navegación tiene riesgos, siempre se confía en su excepcionalidad. El infortunio contradecía las expectativas la mayor parte de las veces cumplidas y que terminaban en riqueza y fama.

Luego de este análisis y de numerosos ejemplos, la autora se centra en el tratamiento del deleite de la escritura y de la rememoración de infortunios en los relatos escritos por sus protagonistas, también de una larga tradición que nos remonta a la retórica antigua. Aquí Carneiro aborda ampliamente las líneas centrales de la Retórica de Aristóteles y su profusa recuperación teórica durante el siglo XVI, fundamentalmente la lectura de Erasmo de Rotterdam y su frase célebre, "agradable es el recuerdo de los males pasados". Sin embargo, la autora observa atinadamente que en los relatos de naufragios, como Naufragio que passou Jorge 
de Albuquerque Coelho, escrito por Bento Teixeira Pinto y la Relación de Manoel de Mesquita Perestrello, sobreviviente de un naufragio en 1553, no concuerdan con dicho tópico ni con el de "magnánimo en la desventura”, demostrando cómo un lugar común se convierte en los textos analizados en sentencia dudosa.

Una de las interesantes conclusiones a las que arriba Carneiro es que las narraciones de naufragios muestran el impacto de la preceptiva retórica pero, a la vez, las tensiones que se generaban en la escritura de infortunios en el siglo XVI. Si bien los tópicos del discurso de la paciencia cristiana, así como otros relacionados con el infortunio, ofrecían un molde para contar el padecimiento, por momentos éstos resultaban estrechos o insuficientes para dar cuenta del dolor vivido. Así, la autora observa otro conflicto en los textos, escasamente relevado: estas crónicas oscilan entre la necesidad de amplificar los males para acercarlos al lector y, a la vez, atender al principio de la brevitas para evitar el fastidio o el descrédito. La lengua del afligido, entonces, producto de esta tensión, se ata y desata entre "el terreno compartido de un modo común de decir y el espacio gris de la desventura, el misterio de la experiencia que transforma lo universal en singular, reto de la palabra que nos precede y que fundamos a la vez” (p. 201).

Retórica del infortunio culmina con un apartado llamado "Dulces adversidades: la paciencia cristiana", capítulo no propiamente retórico, como bien señala la autora, pero de gran utilidad para reconocer la representación del infortunio ya que constituyó la base de muchos "modos de decir la adversidad en el siglo XVI”. El libro incluye, además, un Apéndice con fragmentos de los textos de Jorge de Trebisonda (Libro III de retórica, 1538), Rodolfo Agrícola (el libro III de De la invención dialéctica, 1521) y Nano Mirabelio (Polyanthea, 1552) comentados en el libro, muy útil para los lectores que desconocen el corpus.

En suma, los estudiosos del periodo celebramos publicaciones como esta. Retórica del infortunio resulta un libro fundamental por su análisis detallado y exhaustivo de conceptos retórico-poéticos en crónicas de la conquista de América que se ocupan de los naufragios e infortunios de navegantes ibéricos. Pero no es sólo eso: la autora realiza un compendio completo de los manuales de retórica a los que relaciona estrechamente con su corpus textual y propone un análisis aún más profundo que consiste en dejar de lado el lugar común de la crítica y re-leer textos ya transitados. A fin de cuentas, re-leer es otra forma (y me atrevo a decir, quizá la única) de hacer crítica. 